\title{
SOLUTE REDISTRIBUTION DURING PLANAR AND DENDRITIC GROWTH OF DIRECTIONALLY SOLIDIFIED NI-BASE SUPERALLOY CMSX-10
}

\author{
Seong-Moon Seo ${ }^{1}$, Je-Hyun Lee ${ }^{2}$, Young-Soo Yoo ${ }^{1}$, Chang-Yong Jo ${ }^{1}$, Hirofumi Miyahara ${ }^{3}$, and Keisaku Ogi ${ }^{4}$ \\ ${ }^{1}$ High Temperature Materials Research Group, Korea Institute of Materials Science; 66 Sangnam-dong, Changwon, 641-010, S. Korea \\ ${ }^{2}$ Dept. of Metallurgy and Materials Engineering, Changwon University; 9 Sarim-dong, Changwon, 641-773, S. Korea \\ ${ }^{3}$ Dept. of Materials Science and Engineering, Kyushu University; 744 Motooka, Nishi-ku, Fukuoka, 819-0395, Japan \\ ${ }^{4}$ Oita National College of Technology; 1666 Maki, Oita, 870-0152, Japan
}

Keywords: CMSX-10, segregation, eutectic, directional solidification, superalloy

\begin{abstract}
The solute redistribution behavior during directional solidification of the alloy CMSX-10 with planar and dendritic solid/liquid (S/L) interfaces has been investigated by directional solidification and quenching (DSQ) technique. In particular, the elemental partitioning coefficient during the solidification of primary $\gamma$ and $\gamma / \gamma^{\prime}$ eutectic was quantitatively estimated by electron probe microanalysis (EPMA) on the sample quenched during planar growth of primary $\gamma$ and $\gamma / \gamma^{\prime}$ eutectic, respectively. The EPMA compositional profiles clearly revealed that Scheil solidification occurs during the solidification of primary $\gamma$ with planar S/L interface. Based on this result, the evolution of $\gamma / \gamma^{\prime}$ eutectic volume fraction with respect to the solidification rate in dendritic solidification regimes could be rationalized by considering the back-diffusion effect on decreasing the extent of microsegregation. The comparison of the compositional profiles of $\mathrm{Cr}$ in the planar grown DSQ sample and the local distribution of $\mathrm{Cr}$ in dendritically solidified sample indicated that the solidification of the alloy CMSX-10 completes with the formation of supersaturated $\gamma$ phase after the $\gamma / \gamma^{\prime}$ eutectic reaction.
\end{abstract}

\section{INTRODUCTION}

The enhanced high temperature mechanical properties of advanced Ni-base superalloys are primarily derived from the addition of refractory elements such as Ta, W, Mo, and Re. The addition of these heavy refractory elements has conferred considerable solid solution strengthening with simultaneous increases in high temperature creep resistance. For this reason, the total amount of refractory alloying addition has been gradually increased in the advanced Ni-base superalloys [1,2]. However, the refractory elements segregate severely during solidification $[3,4]$, which often lead to a number of problems such as (i) interdendritic porosity [5], (ii) misoriented grains [6], (iii) freckle formation [6,7], (iv) localized phase instability [8,9], and (v) formation of topologically close-packed (TCP) phases $[9,10]$. While some of these problems were mitigated by the complex step-wise homogenization heat treatment, most result in increased scrap rates. Therefore, it is of great importance to understand the segregation behavior of solute elements when new alloy chemistries are evaluated or numerical models are developed for predicting the extent of microsegregation. In addition, a better understanding of the segregation behavior in the alloy would be helpful to control the solidification microstructures and to identify potential improvements in the processing of current alloys.

So far, several experimental techniques have been implemented to investigate the degree of microsegregation occurring during solidification. Of the techniques available, random sampling approach, which is commonly known as point matrix scan technique, is widely used for characterizing microsegregation in Ni-base superalloys [3,4,7,11-14]. This technique has become prevalent because it allows characterizing microsegregation with no dependence on the plane of examination and simply provides a continuous profile with respect to the fraction of solid $\left(f_{s}\right)$. However, as recently reviewed by Lacaze et al. [15], the cumulative representation of the microsegregation data of multicomponent alloys can be misleading due to the limits of analytical accuracy, to local variability of the microstructure size or to the presence of secondary phase.

Another potential technique involves directional solidification of the alloy followed by quenching (DSQ) [16-18]. In this technique, the partition coefficient of each solute element at the solid/liquid $(\mathrm{S} / \mathrm{L})$ interface is measured by microprobe analysis and hence the extent of segregation can be estimated.

In the present work, the segregation behavior in advanced Ni-base superalloy CMSX-10 has been quantitatively investigated using the DSQ technique. The alloy CMSX-10 was selected as a target alloy because this alloy suffers from severe microsegregation due to its high refractory content $(\mathrm{Ta}+\mathrm{W}+\mathrm{Mo}+\mathrm{Re} \approx 20.5$ wt.\%). Moreover, although CMSX-10 alloy is one of the most advanced Ni-base superalloys, limited information is available in the literatures regarding the quantitative microsegregation data. A series of DSQ experiment were carried out over a wide range of solidification rates, which could encompass planar and dendritic solidification regimes. The influence of the $\mathrm{S} / \mathrm{L}$ interface morphology on the segregation behavior was analyzed through microstructural observation and microprobe analysis. In particular, the partition coefficients of solute elements during the solidification of $\gamma / \gamma^{\prime}$ eutectic were determined on the sample quenched during planar growth of $\gamma / \gamma^{\prime}$ eutectic.

\section{EXPERIMENTAL DETAILS}

The material used in the present work is the advanced Ni-base superalloy CMSX-10 whose chemical composition is listed in Table I. Specimens of $5.0 \mathrm{~mm}$ in diameter and $80 \mathrm{~mm}$ in length were prepared for DS experiments. Directional solidification was made at various solidification rates $(R), R=0.5$ to $100 \mu \mathrm{m} / \mathrm{s}$, under Ar atmosphere using modified Bridgman furnace [19]. The $\mathrm{S} / \mathrm{L}$ interface was preserved by quenching the specimen after a desired volume fraction of original liquid was solidified. During directional solidification, the thermal gradient $(G)$ at the S/L interface was measured by inserting a B-type thermocouple, insulated by a $1.5-\mathrm{mm}$ o.d. alumina tube, into the liquid, which was estimated as about $13.8 \mathrm{~K} / \mathrm{mm}$ at all DS conditions. 
Table I. Chemical composition of the Ni-base superalloy CMSX-10.

\begin{tabular}{|c|c|c|c|c|c|c|c|c|c|c|c|}
\hline & $\mathrm{Al}$ & $\mathrm{Co}$ & $\mathrm{Cr}$ & $\mathrm{Hf}$ & $\mathrm{Mo}$ & $\mathrm{Nb}$ & $\mathrm{Re}$ & $\mathrm{Ta}$ & $\mathrm{Ti}$ & $\mathrm{W}$ & $\mathrm{Ni}$ \\
\hline wt.\% & 5.72 & 3.2 & 2.2 & 0.04 & 0.39 & 0.1 & 6.3 & 8.3 & 0.23 & 5.5 & $\mathrm{Bal}$ \\
\hline
\end{tabular}

(a)

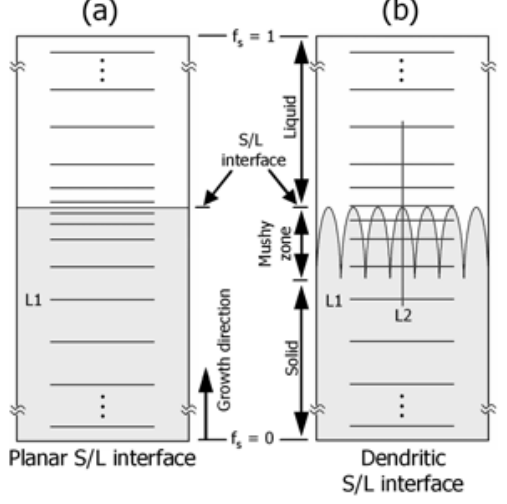

Figure 1. Schematic representation of EPMA line analysis performed on the samples quenched during directional solidification with (a) planar and (b) dendritic S/L interface.

The DSQ samples were cut parallel to the growth direction and polished to observe the S/L interface morphology and to analyze the segregation behavior of the solute elements at each DS condition. The microstructures were characterized by an optical microscope and a scanning electron microscope (SEM; JEOL JSM-5800). Microprobe analyses were carried out to examine the segregation behavior of solute elements using an Electron Probe Microanalyzer (EPMA; Shimadzu EPMA-1600) equipped with four wavelength dispersive spectrometers (WDS) on as-polished microstructural samples. During X-ray sampling, a spot size of 20 $\mu \mathrm{m}$ was used with an accelerating voltage of $20 \mathrm{kV}$ and a beam current of $10 \mathrm{nA}$. All elements except hafnium (0.04 wt.\%) were analyzed utilizing pure elemental standards. Figure 1 shows the schematic representation of EPMA analysis performed on the specimen quenched during DS with planar (Figure 1(a)) and dendritic S/L interface (Figure 1(b)). Two line scan techniques, L1 and L2, were used to determine the composition of solid and liquid at the specified distance from the $\mathrm{S} / \mathrm{L}$ interface. The $\mathrm{L} 1$ line scan was performed perpendicular to the sample growth direction ranging from the first DS solid to the end of the quenched liquid with a prescribed interval. The mean value of each line scan datum was determined as the composition at the specified distance from the $\mathrm{S} / \mathrm{L}$ interface. All line scans utilized a $10 \mu \mathrm{m}$ step size (the distance between two consecutive measurements) along a $1500 \mu \mathrm{m}$ long line to obtain a better statistical representation of the different localized compositions. However, the L1 line scan performed on the specimen exhibiting a dendritic $\mathrm{S} / \mathrm{L}$ interface only represents the average composition of the mushy zone (Figure 1(b)), which is not capable of resolving the composition of dendritic tip. Therefore, in this case, the L2 line scan was performed from the solid to bulk liquid through the dendrite tip (Figure 1(b)) with a $1 \mu \mathrm{m}$ spot size. The composition of the dendrite tip was determined from the L2 line scan results at the dendrite tip.

\section{RESULTS}

\section{$\underline{\mathrm{S} / \mathrm{L} \text { interface morphologies and as-cast microstructures }}$}

The S/L interface morphology during directional solidification depends on the ratio $(G / R)$ between the thermal gradient $(G)$ ahead of the $\mathrm{S} / \mathrm{L}$ interface and the solidification rate $(R)$. Figure 2 shows the $\mathrm{S} / \mathrm{L}$ interface morphologies of DSQ samples that quenched at $f_{s}=0.52$. The planar $\mathrm{S} / \mathrm{L}$ interface was obtained at the solidification rate of $0.5 \mu \mathrm{m} / \mathrm{s}$ (Figure 2(a)). The S/L interface morphology of the alloy developed from planar to cellular and to dendritic with gradually increasing the solidification rate. When the solidification rate further increased to above $5.0 \mu \mathrm{m} / \mathrm{s}$, the S/L interface morphology changed to dendritic with well-developed secondary dendrite arms.

The DS solid shown in Figure 2 corresponds to the primary $\gamma$ phase that developed from the liquid. The fully solidified region in planar and cellular grown samples was composed of only primary $\gamma$, while the as-cast microstructure of dendritically grown samples at $R \geq 5.0 \mu \mathrm{m} / \mathrm{s}$ was characterized by primary $\gamma$ dendrite and $\gamma / \gamma^{\prime}$ eutectic pools in interdendritic area. Figure 3 presents the typical interdendritic micrographs observed at the dendrite bottom of the DSQ sample that solidified at $R=50 \mu \mathrm{m} / \mathrm{s}$. Figure 3(a) and (b) correspond to the SEM micrographs just before and after

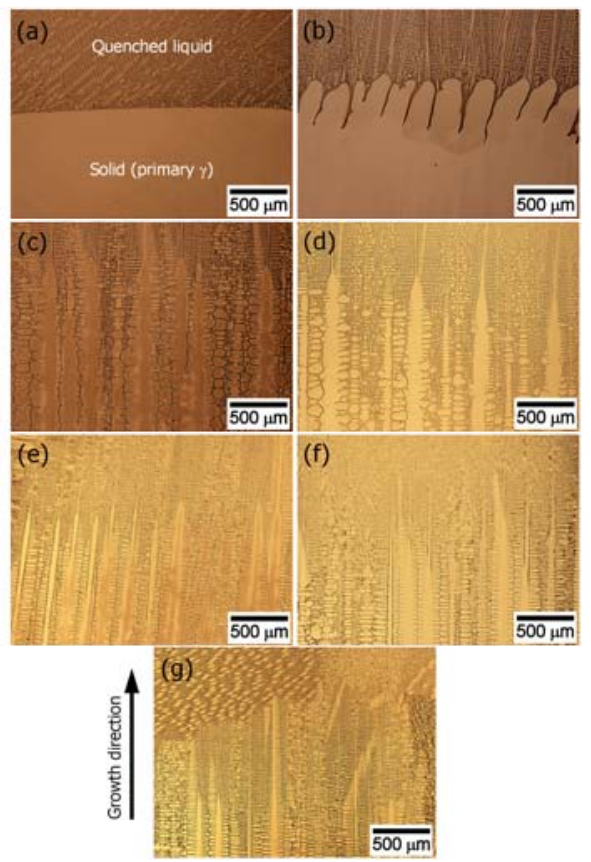

Figure 2. Quenched S/L interface morphologies at various solidification rates. The interface morphologies changed from (a) planar, to (b) cellular, and to (c) - (g) dendritic as the solidification rate gradually increases: The solidification rate is (a) $R=0.5 \mu \mathrm{m} / \mathrm{s}$, (b) $1.0 \mu \mathrm{m} / \mathrm{s}$, (c) $5.0 \mu \mathrm{m} / \mathrm{s}$, (d) 10 $\mu \mathrm{m} / \mathrm{s}$, (e) $25 \mu \mathrm{m} / \mathrm{s}$, (f) $50 \mu \mathrm{m} / \mathrm{s}$, and (g) $100 \mu \mathrm{m} / \mathrm{s}$. 

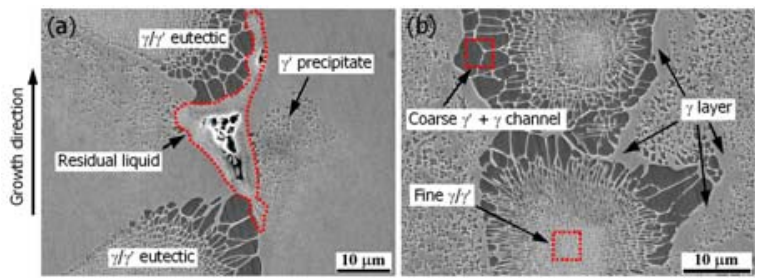

Figure 3. Typical interdendritic microstructures taken at the dendrite bottom of the DSQ sample solidified at $R=50$ $\mu \mathrm{m} / \mathrm{s}$ condition: (a) SEM micrograph showing the $\gamma / \gamma^{\prime}$ eutectic pools and the residual liquid in front of the growing coarse $\gamma / \gamma^{\prime}$ eutectic and (b) fully solidified $\gamma / \gamma^{\prime}$ eutectic morphology and the thin $\gamma$ layer formed in the vicinity of the coarse $\gamma / \gamma^{\prime}$ eutectic.

the final solidification, respectively. It can be seen in Figure 3(a) that the rosette-shaped phases, which is commonly called as the $\gamma / \gamma^{\prime}$ eutectic, and the quenched liquid pool ahead of the growing coarse $\gamma / \gamma^{\prime}$ eutectic. The $\gamma / \gamma^{\prime}$ eutectic can be morphologically characterized by fine $\gamma / \gamma^{\prime}$ network and coarse $\gamma^{\prime}$ phase embedded in narrow $\gamma$ channel as marked in Figure 3(b). It was also found that $\gamma^{\prime}$ particles precipitated near $\gamma / \gamma^{\prime}$ eutectic pools before the final solidification occurs (Figure 3(a)). This result agrees quite well with the microstructural observation of Zhu et al. [20], who reported that large amounts of $\gamma^{\prime}$ particles precipitate at the periphery of $\gamma / \gamma^{\prime}$ eutectic in IN738 alloy before the final solidification occurs. It can be also seen that thin $\gamma$ layer formed ahead of coarse $\gamma / \gamma^{\prime}$ eutectic pools in the fully solidified microstructure of the alloy CMSX-10 (Figure 3(b)).

The formation of $\gamma / \gamma^{\prime}$ eutectic in dendritically solidified alloy was found to be influenced by the solidification rate during directional solidification. The $\gamma / \gamma^{\prime}$ eutectic pool size decreased with increasing the solidification rate, while its volume fraction increased as the solidification rate increases. Figure 4 presents the effect of solidification rate on the $\gamma / \gamma^{\prime}$ eutectic volume fraction in the as-cast microstructure of the alloy. The $\gamma / \gamma^{\prime}$ eutectic volume fraction rapidly increased at and below the solidification rate of 25 $\mu \mathrm{m} / \mathrm{s}$, while it showed a maximum plateau of about $25.2 \%$

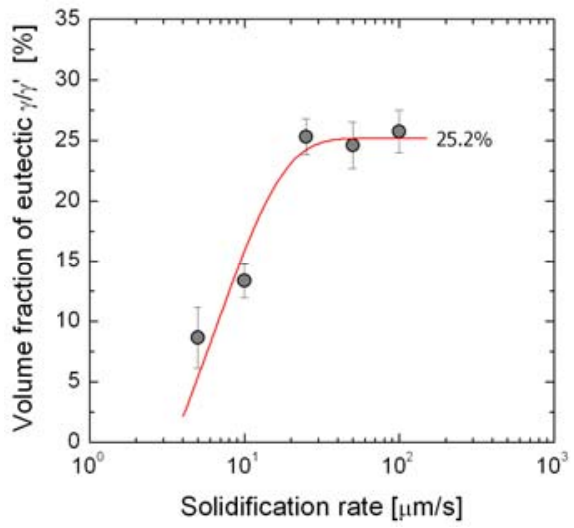

Figure 4. Effect of solidification rate on the volume fraction of $\gamma / \gamma^{\prime}$ eutectic. irrespective of the solidification rate when the solidification rate is higher that $25 \mu \mathrm{m} / \mathrm{s}$. This maximum volume fraction of $\gamma / \gamma^{\prime}$ eutectic is comparable to that of reported elsewhere [13] for the alloy RR3010, which has a similar chemical composition to the alloy CMSX-10.

\section{Solute redistribution during planar growth of primary $\gamma$}

Figure 5 presents the EPMA compositional profiles measured on the longitudinal section of the sample quenched at $f_{s}=0.52$ during directional solidification with planar S/L interface. The composition of $\gamma^{\prime}$ forming elements, such as $\mathrm{Al}, \mathrm{Ta}, \mathrm{Ti}$, and $\mathrm{Nb}$, in DS solid increased as the solidification proceeds and their compositions in quenched liquid were found to be higher than those in the DS solid. The $\mathrm{Ni}$ and $\mathrm{Cr}$ also showed a similar trend with the $\gamma^{\prime}$ forming elements, which indicates that these elements have a segregation tendency to liquid during the solidification of primary $\gamma$. On the other hand, the composition of Co, W, and Re in DS solid gradually decreased as the solidification proceeds. Therefore, it is manifest that these elements have a strong tendency to segregate in primary $\gamma$ rather than in liquid. The Mo was found to be uniformly distributed between primary $\gamma$ and liquid, however, it seems that the segregation tendency of Mo into liquid is slightly high based on the comparison of its average composition between the DS solid and the quenched liquid.

It has to be noted that the compositional profiles of all solute elements in the quenched liquid is found to be almost constant except the compositional gradient layer near the S/L interface of about $1.0 \mathrm{~mm}$, as shown in Figure 5. The compositional gradient layer in the liquid near the $\mathrm{S} / \mathrm{L}$ interface seems to be formed during quenching and this will be discussed later in detail. The uniform distribution of the liquid composition shown in Figure 5 might be due to the strong convection effect in liquid. Trivedi et al. [21] have shown that sample diameter can significantly affect the liquid convection during directional solidification. They have reported that the convection effect is predominant during directional solidification of $\mathrm{Al}-\mathrm{Cu}$ alloy when the sample diameter is larger than $1.0 \mathrm{~mm}$. Therefore, considering that the sample of $5.0 \mathrm{~mm}$ in diameter was employed in the present work, the solute elements accumulated at the S/L interface appear to be transported and mixed by convection, which eventually results in the uniform distribution of solute elements in the entire liquid (Figure 5).

The extent of solute segregation can be determined by measuring the compositions in the solid and liquid at the $\mathrm{S} / \mathrm{L}$ interface. When equilibrium exists at the $\mathrm{S} / \mathrm{L}$ interface during solidification, the equilibrium partition coefficient of solute $i$ is defined as

$$
k_{i}=\frac{C_{S}^{*}}{C_{l}^{*}}
$$

where $C_{s}^{*}$ and $C_{l}^{*}$ are the solute concentration in solid and liquid at the $\mathrm{S} / \mathrm{L}$ interface, respectively [22].

The solute profiles shown in Figure 5 can be schematically illustrated in Figure 6(a) and (b), in the case of solute element with $k_{i}<1$ and $k_{i}>1$, respectively. In Figure $6, C_{0}$ is the initial composition and $\bar{C}_{l}$ is the average composition of quenched liquid where the composition near the compositional gradient layer $(\delta)$ formed at the $\mathrm{S} / \mathrm{L}$ interface is excluded. The 
$k_{i}^{0} C_{0}$ represents the composition of the first solid formed from liquid. This value was measured from Figure 5 by the extrapolation of the solute profiles in the solid to $f_{s}=0$, so that the partition coefficient at the initial stage of solidification, $k_{i}^{0}$, could be estimated. If it is assumed that the $C_{l}^{*}$ is affected by quenching during directional solidification and if the liquid composition before the quenching is assumed to be equal to $\bar{C}_{l}$, the extent of segregation can be measured by employing the effective partition coefficient ( $k_{i}^{\text {eff }}$ ) as

$$
k_{i}^{e f f}=\frac{C_{s}^{*}}{\bar{C}_{l}}
$$

, and $k_{i}^{\text {eff }}$ values have to be used for estimating the extent of segregation during directional solidification where a severe liquid convection occurs.

The EPMA compositions and the partition coefficients, $k_{i}, k_{i}^{0}$, and $k_{i}^{\text {eff }}$, which were measured on the quenched planar $\mathrm{S} / \mathrm{L}$ interface shown in Figure 5, are summarized in Table II. It was found that the estimated partition coefficient of $\mathrm{Al}, \mathrm{Cr}, \mathrm{Nb}, \mathrm{Mo}$, $\mathrm{Ta}$, and $\mathrm{Ti}$ was less than unity, while that of Co, Re, and $\mathrm{W}$ was greater than unity. Of all solute elements that were presented in Table II, Ti and heavy refractory elements such as Re, Ta, and W exhibited particularly strong segregation tendency. This segregation tendency was found to be comparable with those

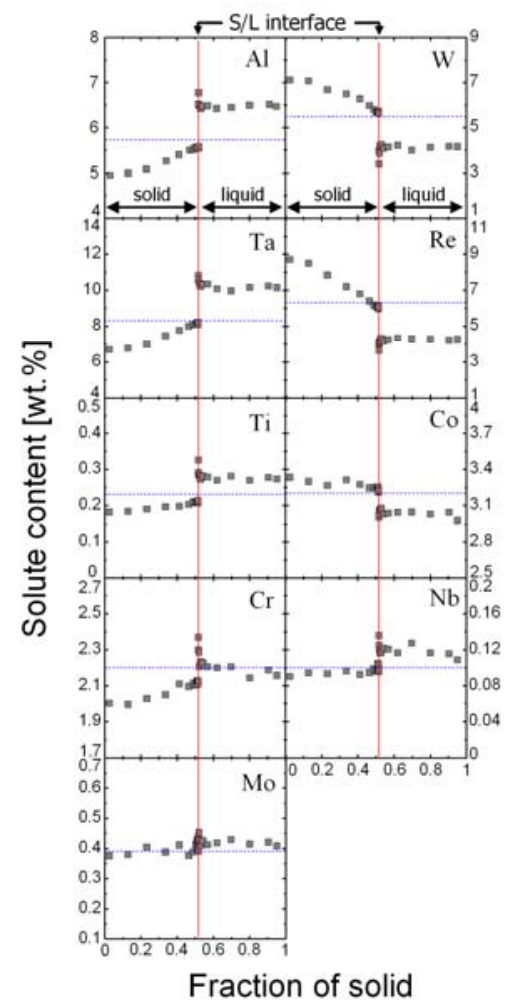

Figure 5. EPMA compositional profiles of solute elements measured on the sample quenched at $f_{s}=0.52$ during directional solidification with planar S/L interface.

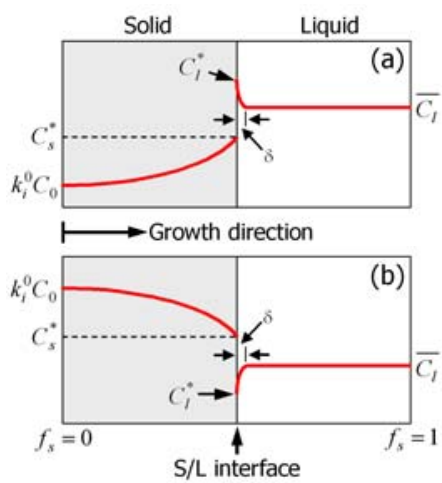

Figure 6. Schematic representation of the solute profiles shown in Figure 5: (a) the partition coefficient is less than unity $(k<1)$ and (b) $k>1$.

reported for dendritically solidified commercial single crystal superalloys $[3,4,7,11]$ and model single crystal superalloys $[6,23]$.

During solidification, if the diffusion in solid is small enough to neglect, the partition coefficient at the initial stage of solidification, $k_{i}^{0}$, would be nearly same as $k_{i}$, which is measured at the quenched $\mathrm{S} / \mathrm{L}$ interface where the solidification is proceeded to some extent. However, if $C_{l}^{*}$ is affected by the quenching during solidification, $k_{i}^{0}$ would be equal to $k_{i}^{\text {eff }}$. In order to identify whether $C_{l}^{*}$ is affected by the quenching or not, $k_{i}$ and $k_{i}^{\text {eff }}$ values of each solute element were compared with $k_{i}^{0}$ values. The results showed that $k_{i}^{0}$ values are close to $k_{i}^{\text {eff }}$ rather than $k_{i}$ in most of the solute elements (Table II). In particular, the solute elements exhibiting a severe segregation tendency such as Re, $\mathrm{W}, \mathrm{Ta}$, and $\mathrm{Ti}$ showed more clear differences. This indicates that $C_{l}^{*}$ in Figure 6 would be formed as an artifact of the quenching during directional solidification.

\section{Solute redistribution during dendritic growth}

Figure 7 shows the EPMA compositional profiles of major solute elements (Al, Ta, Re, and $\mathrm{W}$ ) measured on the samples quenched at $f_{s}=0.52$ during directional solidification with planar ( $R=$ $0.5 \mu \mathrm{m} / \mathrm{s}$ ) and dendritic ( $R=50 \mu \mathrm{m} / \mathrm{s}$ ) S/L interface. Note that the composition in the DS part of the dendritically solidified sample represents the average composition of dendrite and interdendritic region at the same distance from the dendrite tip. It becomes clear from the figure that the average composition of solutes in the dendritically solidified sample is not affected by the progress of solidification compared to that of the sample solidified with planar S/L interface. In addition, the average solute composition of the dendritically solidified sample was nearly $C_{0}$ of each solute element regardless of the solidification distance. This result confirms that segregation dominantly occurs to lateral direction than along the primary dendrite growth direction during directional solidification with dendritic S/L interface.

\section{Solute redistribution during $\gamma / \gamma^{\prime}$ eutectic formation}

It was shown in Figure 4 that the as-cast microstructure of dendritically solidified CMSX-10 exhibited a quite high volume fraction of $\gamma / \gamma^{\prime}$ eutectic. In particular, when the solidification rate 


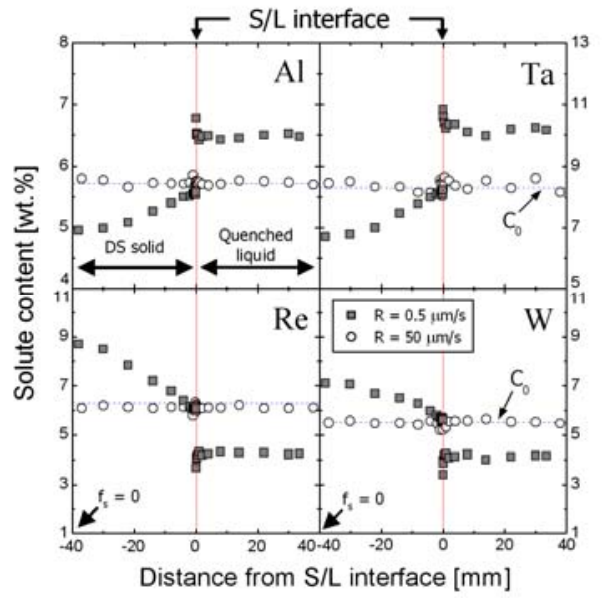

Figure 7. Comparison of the EPMA compositional profiles of major solute elements measured on the samples quenched during directional solidification with planar $(R=0.5 \mu \mathrm{m} / \mathrm{s})$ and dendritic ( $R=50 \mu \mathrm{m} / \mathrm{s}$ ) S/L interfaces.

is higher than $25 \mu \mathrm{m} / \mathrm{s}$, the volume fraction of $\gamma / \gamma^{\prime}$ eutectic was as high as about $25 \%$. Therefore, in order to understand the whole segregation behavior of solute elements in CMSX-10, it is imperative to quantitatively analyze the segregation behavior during the solidification of $\gamma / \gamma^{\prime}$ eutectic as well as the solidification of primary $\gamma$.

The quantitative solute redistribution behavior during $\gamma / \gamma^{\prime}$ eutectic formation was evaluated in the sample quenched during planar solidification of $\gamma / \gamma^{\prime}$ eutectic. Figure 8(a) shows the schematic of the sample used for the EPMA analysis. Based on the microstructural observation, it was found that the planar solidification of the primary $\gamma$ completes at $f_{s}=0.75$ and after that the $\gamma / \gamma^{\prime}$ eutectic forms from the remaining liquid. Figure 8(b) and (c) present the optical micrographs of the quenched planar $\mathrm{S} / \mathrm{L}$ interface and the transverse section of the planar solidified $\gamma / \gamma^{\prime}$ eutectic region, respectively. The bright grey phases in Figure 8(b) and (c) correspond to the $\gamma^{\prime}$ phases, while dark grey phases are $\gamma$ phases. The planar grown $\gamma / \gamma^{\prime}$ eutectic was composed of rodshaped $\gamma^{\prime}$, which exhibits an elongated morphology along the growth direction, embedded in the eutectic $\gamma$.

Figure 9 shows the EPMA profiles of solute elements measured on the sample shown in Figure 8(a). The solute profiles in the region of planar solidified primary $\gamma\left(f_{s}=0\right.$ to 0.75$)$ were found to be varied as the same manner as those shown in Figure 5, while the solute profiles in the region of $\gamma / \gamma^{\prime}$ eutectic formation $\left(f_{s}=\right.$ 0.75 to 0.83 ) exhibited quite different aspects. If it is defined that $C_{\gamma}^{s m}$ is the composition of maximum solubility of solutes at the completion of primary $\gamma$ at $f_{s}=0.75$ and $C_{e u}^{0}$ is the initial composition of $\gamma / \gamma^{\prime}$ eutectic at the same $f_{s}$, the $C_{e u}^{0}$ value of the $\gamma^{\prime}$ forming elements such as $\mathrm{Al}, \mathrm{Ta}, \mathrm{Ti}$, and $\mathrm{Nb}$ exhibited higher than $C_{\gamma}^{s m}$ values. Considering that $\gamma / \gamma^{\prime}$ eutectic is composed of $\gamma$ and $\gamma^{\prime}$ phases, and a higher volume fraction of $\gamma^{\prime}$ phase in $\gamma / \gamma^{\prime}$ eutectic, this result indicates that the solubility of these elements in $\gamma^{\prime}$ phase is higher than in $\gamma$ phase. Conversely, the other solute elements such as Co, Cr, Mo, Re, and W exhibited that the $C_{e u}^{0}$ values are lower than $C_{\gamma}^{s m}$, which implies that the solubility of these elements in $\gamma^{\prime}$ phase is lower than that in $\gamma$ phase [23,24].

It has to be noted that the solute profiles in the quenched liquid shown in Figure 9 showed a clear existence of diffusion boundary layer from the $\mathrm{S} / \mathrm{L}$ interface to the liquid end, which is different from the result shown in Figure 5 where the composition of quenched liquid is uniform throughout the liquid. This seems to be related to the combined effect of (i) decrease in liquid convection as the remaining liquid zone becomes shorter during further progress of solidification (The length of the quenched liquid zone in Figure 9 is about $12.7 \mathrm{~mm}$, which is about $1 / 3$ of the liquid length shown in Figure 5) and (ii) the interaction between solute boundary layer and the specimen end (The end of the liquid zone can be regarded as being a perfectly impermeable wall which imposes a zero flux condition at that point).

The extent of the segregation during the solidification of $\gamma / \gamma^{\prime}$ eutectic can be represented by defining the partition coefficient $k_{i}^{\gamma / \gamma^{\prime}}$ as follows:

$$
k_{i}^{\gamma / \gamma^{\prime}}=\frac{C_{e u}^{*}}{C_{l, e u}^{*}}
$$

where $C_{e u}^{*}$ is the composition of the $\gamma / \gamma^{\prime}$ eutectic at the S/L interface and $C_{l, e u}^{*}$ is the liquid composition at the $\mathrm{S} / \mathrm{L}$ interface

Table II. EPMA compositions and various partition coefficients measured on the quenched planar S/L interface shown in Figure 5.

\begin{tabular}{|c|c|c|c|c|c|c|c|c|c|}
\hline & $\mathrm{Al}$ & Co & $\mathrm{Cr}$ & Mo & $\mathrm{Nb}$ & $\operatorname{Re}$ & Та & $\mathrm{Ti}$ & W \\
\hline \multicolumn{10}{|c|}{ EPMA compositions (wt \%) } \\
\hline$C_{s}^{*}$ & 5.55 & 3.23 & 2.12 & 0.41 & 0.10 & 6.06 & 8.17 & 0.21 & 5.66 \\
\hline$C_{l}^{*}$ & 6.77 & 3.0 & 2.37 & 0.45 & 0.14 & 3.66 & 10.83 & 0.33 & 3.38 \\
\hline $\bar{C}_{l}$ & 6.47 & 3.03 & 2.18 & 0.42 & 0.12 & 4.26 & 10.11 & 0.27 & 4.12 \\
\hline$k_{i}^{0} C_{0}$ & 4.89 & 3.34 & 1.99 & 0.38 & 0.09 & 9.02 & 6.52 & 0.18 & 7.32 \\
\hline \multicolumn{10}{|c|}{$\underline{\text { Partition coefficients }}$} \\
\hline$k_{i}$ & 0.82 & 1.08 & 0.89 & 0.92 & 0.74 & 1.66 & 0.76 & 0.64 & 1.68 \\
\hline$k_{i}^{e f f}$ & 0.86 & 1.07 & 0.97 & 0.99 & 0.86 & 1.42 & 0.81 & 0.76 & 1.37 \\
\hline$k_{i}^{0}$ & 0.85 & 1.04 & 0.91 & 0.98 & 0.92 & 1.43 & 0.79 & 0.78 & 1.33 \\
\hline
\end{tabular}


before quenching, respectively. The $C_{e u}^{*}$ was determined by the linear extrapolation of EPMA data within the $\gamma / \gamma^{\prime}$ eutectic grown region $\left(0.75 \leq f_{s} \leq 0.83\right)$. However, it has be careful to determine $C_{l, e u}^{*}$ value. As previously discussed above, the liquid composition near the $\mathrm{S} / \mathrm{L}$ interface was affected by the quenching. This quenching effect was estimated to be within about $1.0 \mathrm{~mm}$ from the $\mathrm{S} / \mathrm{L}$ interface by analyzing the EPMA profiles in the liquid region. Therefore, the EPMA compositions near the S/L interface shown in Figure 9 were also assumed to be affected by the quenching. The $C_{l, e u}^{*}$ was determined at the S/L interface by extrapolating the EPMA profiles in liquid region where the EPMA data within $1.0 \mathrm{~mm}$ from the $\mathrm{S} / \mathrm{L}$ interface was excluded.

Table III summarizes the $C_{\gamma}^{s m}, C_{e u}^{0}, C_{e u}^{*}$, and $C_{l, e u}^{*}$ values, which were determined from Figure 9. The partition coefficient $k_{i}^{\gamma / \gamma^{\prime}}$ of each element was also shown in Table III. The heavy refractory elements such as Ta, Re, and $\mathrm{W}$ exhibiting strong segregation tendency during the solidification of primary $\gamma$ were found to exhibit no significant segregation tendency during the $\gamma / \gamma^{\prime}$ eutectic formation. The $k_{i}^{\gamma^{\gamma} \gamma^{\prime}}$ of these elements were estimated as close to unity as shown in Table III. Although $\mathrm{Ti}$ is a major $\gamma^{\prime}$ forming element, the $k_{T i}^{\gamma^{\prime} \gamma^{\prime}}$ was estimated as 0.82 and showed a segregation tendency to liquid. Cobalt segregated to solid during the solidification of primary $\gamma$, while it slightly enriched in liquid during the $\gamma / \gamma^{\prime}$ eutectic formation $\left(k_{C o}^{\gamma / \gamma^{\prime}}=\right.$ 0.94). The $k_{A l}^{\gamma / \gamma^{\prime}}$ value was estimated as 1.03. It means that the segregation tendency of $\mathrm{Al}$ into growing $\gamma / \gamma^{\prime}$ eutectic is slightly higher than into liquid during $\gamma / \gamma^{\prime}$ eutectic formation. This result is confirmed by the EPMA profiles of $\mathrm{Al}$ in liquid region near the S/L interface where the EPMA profiles clearly indicate the minimum $\mathrm{Al}$ content at the $\mathrm{S} / \mathrm{L}$ interface. Therefore, it is expected that the $\mathrm{Al}$ content in the residual liquid would be continually decreased as the formation of $\gamma / \gamma^{\prime}$ eutectic proceeds further. The solute elements showing the most severe segregation tendency during $\gamma / \gamma^{\prime}$ eutectic formation were found to be $\mathrm{Cr}$, Mo, and $\mathrm{Nb}$. These elements have a strong tendency to segregate in liquid during $\gamma / \gamma^{\prime}$ eutectic formation than the primary $\gamma$ solidification.

(a)
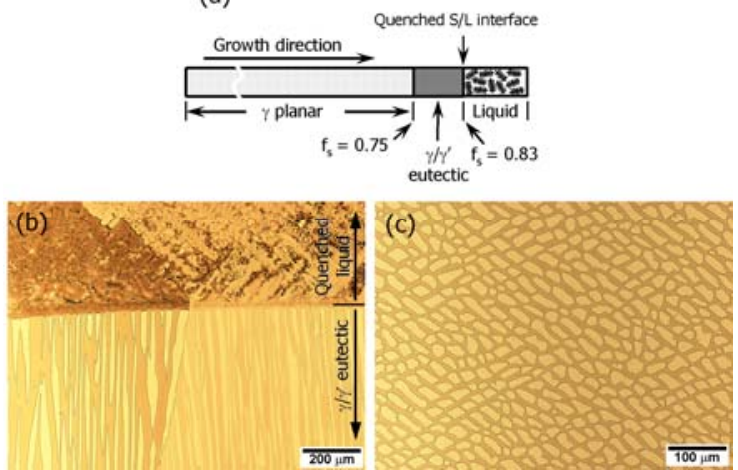

Figure 8. Microstructures of the sample quenched at $f_{s}=$ 0.83 during directional solidification with planar S/L interface: (a) schematic of the quenched DS sample, (b) longitudinal optical micrograph showing the quenched S/L interface of planar solidified $\gamma / \gamma^{\prime}$ eutectic, and (c) transverse micrograph of the planar solidified $\gamma / \gamma^{\prime}$ eutectic region.

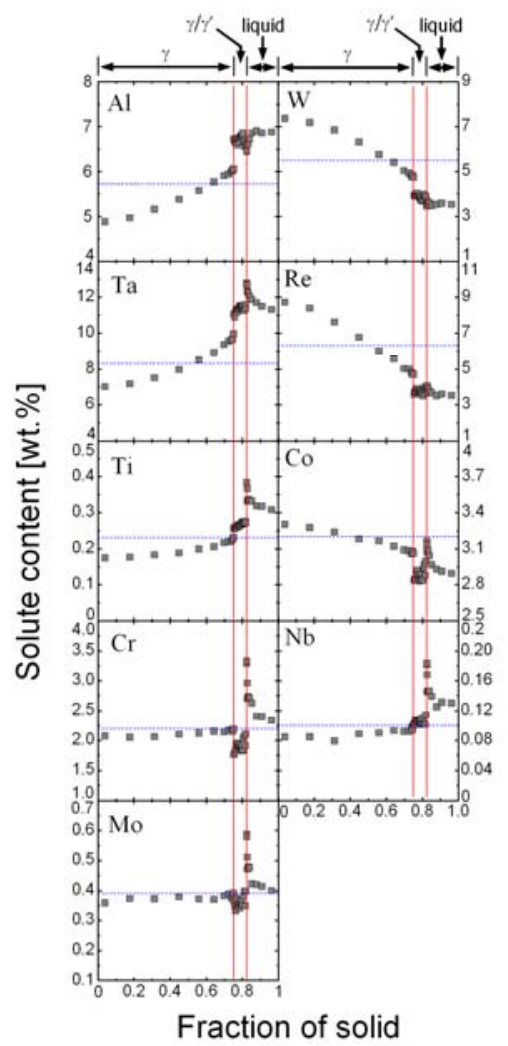

Figure 9. EPMA compositional profiles of solute elements measured on the sample quenched during planar solidification of $\gamma / \gamma^{\prime}$ eutectic.

Considering that these elements are accumulated in liquid during the solidification of $\gamma / \gamma^{\prime}$ eutectic, it is expected that relatively large amounts of $\mathrm{Cr}$, Mo, and $\mathrm{Nb}$ will be enriched in the final liquid of the alloy CMSX-10.

\section{DISCUSSION}

Determination of the partition coefficients using the DSQ technique

Regarding the measurement of the partition coefficient during solidification, Sung et al. [16] have reported that the partition coefficient measured at the quenched planar S/L interface by microprobe analyses yields the equilibrium partition coefficient, because the solidification rates are so slow, and there are no effects of interfacial kinetics. However, as previously described above, the liquid composition near the S/L interface appeared to be significantly influenced by the quenching during directional solidification. In order to identify the quenching effect, the solute compositions in the DS solid were calculated by Scheil model [25] and the calculation results were compared with the EPMA profiles of each solute element. Based on the Scheil equation, the solute composition in solid $\left(C_{s}\right)$ and in liquid $\left(C_{l}\right)$ is given by

$$
C_{s}=k C_{0}\left(1-f_{s}\right)^{k-1}
$$




$$
C_{l}=C_{0}\left(1-f_{s}\right)^{k-1}
$$

where $k$ is the partition coefficient. Two kinds of $C_{s}$ calculation were made as a function of $f_{s}$ with different partition coefficients, $k_{i_{*}}$ and $k_{i}^{\text {eff }}$. Note that $k_{i}$ and $k_{i}^{\text {eff }}$ are obtained by using the $C_{l}^{*}$ and $\bar{C}_{l}$ as a liquid composition at the S/L interface, respectively. The solute profiles for $\mathrm{W}$ and $\mathrm{Re}$, which exhibited the biggest difference between $k_{i}$ and $k_{i}^{\text {eff }}$ values (Table II), were presented in Figure 10 as an example. Figure 10 clearly showed that the experimental profiles agree quite well with the calculation results using $k_{i}^{\text {eff }}$ on both solute elements of $\mathrm{W}$ and Re. This result would mean that the liquid composition of $C_{l}^{*}$ shown in Figure 5 and 6 is an artifact generated by the quenching during directional solidification. Therefore, it is clear that one has to measure the $k_{i}^{\text {eff }}$ using the DSQ technique for the estimation of equilibrium partition coefficient when there exist an active melt convection. In addition, the results shown in Figure 5 and 10 confirm that Scheil solidification indeed occurs during the planar solidification of primary $\gamma$ in the alloy CMSX-10.

\section{Comparison of planar vs. dendritic solidification}

During directional solidification, the solute element segregates along the growth direction of solid depending on its partition coefficient. Therefore, in the case of planar solidification condition, the solute content at the final solid macroscopically differs from that of the first solid (Figure 5 and 9). On the other hand, in the case of dendritic solidification, most of the segregation occurs rather laterally than along the growth direction of the primary dendrite due to the limited curvature of the dendrite tip. For this reason, in dendritic solidification with higher solidification rates, the average solute content at a given distance from the dendrite tip nearly equals to $C_{0}$ as shown in Figure 7 . Therefore, it is suggested that the interdendritic microsegregation could represent the entire segregation behavior of solute elements in dendritic solidification with higher solidification rates.

As an example for interdendritic microsegregation, the EPMA mapping analysis was carried out on the transverse section of the dendritically solidified ( $R=50 \mu \mathrm{m} / \mathrm{s}$ ) as-cast sample and the results were presented in Figure 11. It was found that the solute elements with $k_{i}^{\text {eff }}<1$ such as $\mathrm{Al}$, $\mathrm{Ta}$, and $\mathrm{Cr}$ enriched in

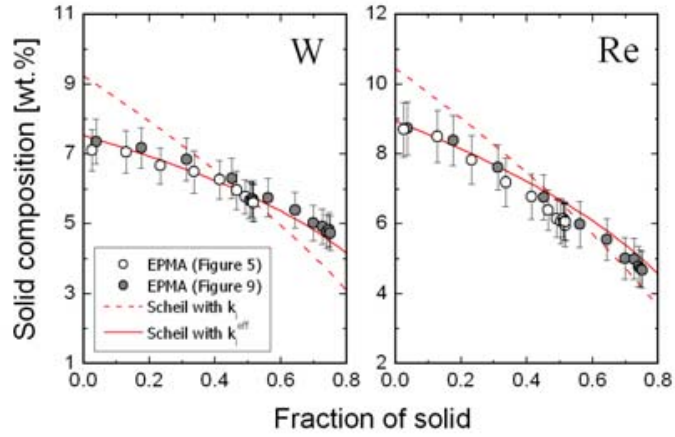

Figure 10. Comparison of the EPMA profiles with the calculated compositional profiles in solid using Scheil equation with $k_{i}$ and $k_{i}^{\text {eff }}$.

interdendritic region rather than in dendrite core. In contrast, the heavy refractory elements such as $\mathrm{W}$ and Re that have $k_{i}^{\text {eff }}>1$ enriched in the dendrite core region. Consequently, considering that the solidification initiates at the dendrite core and proceeds toward the interdendritic region, it can be suggested that the interdendritic microsegregation behavior observed in dendritically solidified sample qualitatively corresponds to the macroscopic segregation behavior in the planar solidified sample (Figure 5).

\section{Effect of back-diffusion during dendritic solidification}

Compared to the DS with planar S/L interface that exhibits Scheil solidification (no diffusion in solid), the diffusion distance is as small as a scale of dendrite arm spacing in dendritic solidification, which may give rise to the decreases in interdendritic microsegregation by back-diffusion in solid. It has been known that the extent of back-diffusion in solid during solidification is proportional to the local solidification times and the diffusivity of solute element in solid $\left(D_{s}\right)$, while it is inversely proportional to the square of the diffusion distance and the cooling rate $(G \cdot R)$ [26]. Regarding the influence of the cooling rate on the extent of back-diffusion, El-Bagoury et al. [27] have recently shown that the microsegregation of $\mathrm{Nb}$ between the dendrite core and interdendritic region decreases at lower cooling rate of about 1.0 $\mathrm{K} / \mathrm{min}$ by back-diffusion in alloy IN718. However, they have

Table III. Compositions measured from the EPMA solute profiles in Figure 9 and estimated partition coefficients of solute elements during the solidification of $\gamma / \gamma^{\prime}$ eutectic.

\begin{tabular}{|c|c|c|c|c|c|c|c|c|c|}
\hline & $\mathrm{Al}$ & Co & $\mathrm{Cr}$ & Mo & $\mathrm{Nb}$ & $\operatorname{Re}$ & Ta & $\mathrm{Ti}$ & W \\
\hline \multicolumn{10}{|c|}{ EPMA compositions, wt \% (at \%) } \\
\hline$C_{\gamma}^{s m}$ & $\begin{array}{c}6.06 \\
(13.9)\end{array}$ & $\begin{array}{c}3.06 \\
(3.22)\end{array}$ & $\begin{array}{c}2.19 \\
(2.62)\end{array}$ & $\begin{array}{c}0.39 \\
(0.25)\end{array}$ & $\begin{array}{c}0.10 \\
(0.17)\end{array}$ & $\begin{array}{c}4.69 \\
(1.56)\end{array}$ & $\begin{array}{c}9.97 \\
(3.42)\end{array}$ & $\begin{array}{c}0.23 \\
(0.30)\end{array}$ & $\begin{array}{c}4.74 \\
(1.60)\end{array}$ \\
\hline$C_{e u}^{0}$ & $\begin{array}{c}6.70 \\
(15.1)\end{array}$ & $\begin{array}{c}2.84 \\
(2.93)\end{array}$ & $\begin{array}{c}1.80 \\
(2.10)\end{array}$ & $\begin{array}{c}0.35 \\
(0.22)\end{array}$ & $\begin{array}{c}0.10 \\
(0.07)\end{array}$ & $\begin{array}{c}3.71 \\
(1.21)\end{array}$ & $\begin{array}{l}11.11 \\
(3.73)\end{array}$ & $\begin{array}{c}0.25 \\
(0.32)\end{array}$ & $\begin{array}{c}3.95 \\
(1.31)\end{array}$ \\
\hline$C_{e u}^{*}$ & $\begin{array}{c}6.70 \\
(15.2)\end{array}$ & $\begin{array}{c}2.93 \\
(3.05)\end{array}$ & $\begin{array}{c}2.03 \\
(2.39)\end{array}$ & $\begin{array}{c}0.38 \\
(0.24)\end{array}$ & $\begin{array}{c}0.11 \\
(0.07)\end{array}$ & $\begin{array}{c}3.74 \\
(1.23)\end{array}$ & $\begin{array}{l}11.58 \\
(3.92)\end{array}$ & $\begin{array}{c}0.28 \\
(0.36)\end{array}$ & $\begin{array}{c}3.79 \\
(1.26)\end{array}$ \\
\hline$C_{l, e u}^{*}$ & $\begin{array}{c}6.53 \\
(15.1)\end{array}$ & $\begin{array}{c}3.13 \\
(3.31)\end{array}$ & $\begin{array}{c}2.83 \\
(3.39)\end{array}$ & $\begin{array}{c}0.52 \\
(0.34)\end{array}$ & $\begin{array}{c}0.16 \\
(0.11)\end{array}$ & $\begin{array}{c}3.93 \\
(1.32)\end{array}$ & $\begin{array}{l}12.40 \\
(4.27)\end{array}$ & $\begin{array}{c}0.34 \\
(0.44)\end{array}$ & $\begin{array}{c}3.59 \\
(1.22)\end{array}$ \\
\hline \multicolumn{10}{|c|}{$\underline{\text { Partition coefficient }}$} \\
\hline$k_{i}^{\gamma / \gamma^{\prime}}$ & 1.03 & 0.94 & 0.72 & 0.72 & 0.67 & 0.95 & 0.93 & 0.82 & 1.06 \\
\hline
\end{tabular}


shown that the back-diffusion of Nb significantly decreased to be neglected when the cooling rate increases to $10 \mathrm{~K} / \mathrm{min}$. Tewari et al. [17] have reported a similar result, that the contribution of back-diffusion to microsegregation is negligible for the elements $\mathrm{Ta}, \mathrm{Al}, \mathrm{Ti}, \mathrm{Co}$, and $\mathrm{W}$, when the cooling rate is about $7.3 \mathrm{~K} / \mathrm{min}$ in the Ni-base superalloy PWA-1480. In contrast to these studies, Thirumalai et al. [14] have reported that their microsegregation results cannot be rationalized without acknowledging the occurrence of back-diffusion during directional solidification of the experimental Ni-base superalloy RR2100 at a cooling rate of $10 \mathrm{~K} / \mathrm{min}(G=10 \mathrm{~K} / \mathrm{mm}$ and $R=1.0 \mathrm{~mm} / \mathrm{min})$. Nevertheless, they could not explain why the solute content of the dendrite core in mushy zone from the dendrite tip to the dendrite bottom remains unchanged. In the presence of significant back-diffusion, the solute content at the dendrite core $\left(f_{s} \approx 0\right)$, which is located near the dendrite bottom, would have been higher than the $k_{i}^{\text {eff }} C_{0}$ for the elements with $k_{i}^{\text {eff }}<1$, and lower than the $k_{i}^{\text {eff }} C_{0}$ for the elements with $k_{i}^{\text {eff }}>1[28,29]$. Consequently, it can be concluded that back-diffusion in solid indeed occurs during solidification, but its influence on decreasing the microsegregation becomes negligible depending on the diffusivity of each solute element when the cooling rate is increased up to a certain limit.

The extent of back-diffusion at different solidification rates in $\mathrm{Ni}$ base superalloys can be evaluated on the basis of $\gamma / \gamma^{\prime}$ eutectic volume fraction, because all of the $\gamma^{\prime}$ forming elements segregate to liquid during the solidification of primary $\gamma$ (Figure 5). Therefore, it can be said that the higher the $\gamma / \gamma^{\prime}$ eutectic volume fraction, the greater the extent of microsegregation, i.e. the influence of back-diffusion on decreasing the microsegregation is small. It has been shown in Figure 4 that the volume fraction of $\gamma / \gamma^{\prime}$ eutectic increases with increasing the solidification rate in the range of $R=5.0$ to $25 \mu \mathrm{m} / \mathrm{s}$, and then shows a maximum plateau of about $25 \%$. This result can be recognized that the backdiffusion in solid is deactivated as the solidification rate increases and becomes too small to affect on the microsegregation, when the solidification rate is higher than about $25 \mu \mathrm{m} / \mathrm{s}$. Furthermore, the maximum volume fraction of $\gamma / \gamma^{\prime}$ eutectic measured on the dendritically solidified as-cast microstructures corresponds well to the $\left(1-f_{s}\right)$ in planar solidification (Scheil solidification) condition, where $f_{s}$ is the fraction solid that $\gamma / \gamma^{\prime}$ eutectic begins to form ( $f_{s}=0.75$ in Figure 8(a) and 9). Therefore, it is concluded that the back-diffusion effect on decreasing the microsegregation obviously becomes very small, when the solidification rate is higher than $25 \mu \mathrm{m} / \mathrm{s}$ (the corresponding cooling rate $G \cdot R=20.7 \mathrm{~K} / \mathrm{min}$ ) in the alloy CMSX -10 .

\section{$\underline{\text { Final solidification of CMSX-10 }}$}

The solidification of most single crystal Ni-base superalloys including the alloy CMSX-10 initiates with the formation of primary $\gamma$. During the growth of primary $\gamma$, the solute elements with $k_{i}^{\text {eff }}<1$ enriched in the liquid ahead of the growing S/L interface. As shown in Table II, the solute elements with $k_{i}^{\text {eff }}<1$ are $\mathrm{Cr}$, Mo, and $\gamma^{\prime}$ forming elements such as $\mathrm{Al}$, Ta, $\mathrm{Ti}$, and $\mathrm{Nb}$, Therefore, as the solidification proceeds, these elements are continually accumulated in liquid, and if the composition of solid at the $\mathrm{S} / \mathrm{L}$ interface exceeds the solubility limit of primary $\gamma$, the eutectic reaction of $L \rightarrow \gamma+\gamma^{\prime}$ would occur. Generally, it has been known that the solidification of the advanced Ni-base superalloys completes with the formation of $\gamma / \gamma^{\prime}$ eutectic $[4,7,17,29,30]$.

The $\gamma / \gamma^{\prime}$ eutectic was observed with rosette shape in dendritically solidified CMSX-10 alloy (Figure 3). This rosette-shaped $\gamma / \gamma^{\prime}$ eutectic can be morphologically characterized by two distinct regions; fine lamellar $\gamma / \gamma^{\prime}$ structure and coarse eutectic $\gamma^{\prime}$ embedded in thin $\gamma$ channels, as denoted in Figure 3(b). Recently, D'Souza and Dong [31] have suggested that these regions formed by independent two reactions, i.e. coarse $\gamma^{\prime}$ particles nucleate from $\gamma$ at the $\gamma / \mathrm{L}$ interface and coarsen via a peritectic reaction of $\mathrm{L}+\gamma$ $\rightarrow \gamma^{\prime}$ after the formation of primary $\gamma$ dendrite. Then, the solidification terminates with the formation of fine lamellar $\gamma / \gamma^{\prime}$ between the coarsened $\gamma^{\prime}$ particles by eutectic reaction. However, the careful microstructural observations near the dendrite bottom revealed that the residual liquid is always located in front of the coarse $\gamma^{\prime}$ particles (Figure 3(a)), which agrees well with the results
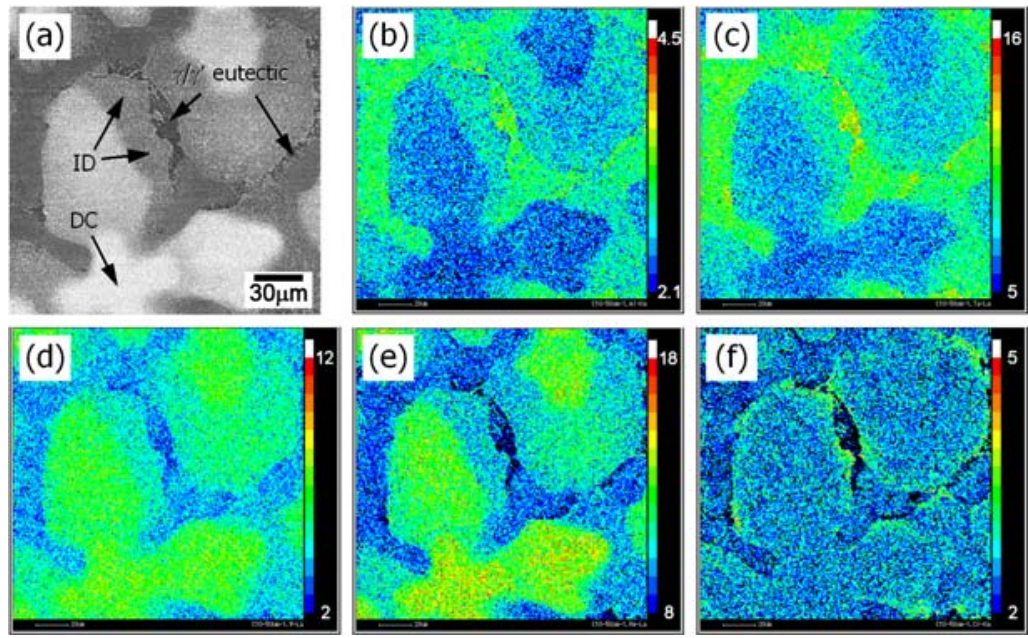

Figure 11. X-ray mapping micrographs showing the interdendritic microsegregation in as-cast CMSX-10 alloy ( $R=50 \mu \mathrm{m} / \mathrm{s})$ : (a)

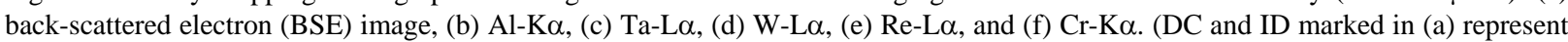
the dendrite core and interdendritic area, respectively.) 
of Walter et al. [29] and Zhu et al. [24]. This result clearly indicates that the solidification of $\gamma / \gamma^{\prime}$ eutectic initiates with the formation of fine $\gamma / \gamma^{\prime}$ and proceeds toward the coarse $\gamma^{\prime}$ particles.

One more thing has to be concerned is the solidification of the alloy CMSX-10 does not appear to be completed with the formation of coarse $\gamma / \gamma^{\prime}$ eutectic. This can be deduced from analyzing the segregation pattern of $\mathrm{Cr}$ during the $\gamma / \gamma^{\prime}$ eutectic growth with planar S/L interface (Figure 9) and the local distribution of $\mathrm{Cr}$ in the interdendritic region of dendritically solidified sample (Figure 11(f)). The EPMA profile of $\mathrm{Cr}$ shown in Figure 9 revealed that $\mathrm{Cr}$ enriches in liquid during the growth of $\gamma / \gamma^{\prime}$ eutectic because of its very low solubility in $\gamma^{\prime}$ phase $[23,24]$. As a result, the compositions of $\mathrm{Cr}$ in $\gamma / \gamma^{\prime}$ eutectic were lower than those in the entire preceding primary $\gamma$. In addition, the Cr concentration in the quenched liquid was higher than those in the primary $\gamma$ and $\gamma / \gamma^{\prime}$ eutectic. It is obvious from this result that the highest Cr-rich area will form at the last stage of solidification.

In the meantime, the $\mathrm{Cr}$ distribution in dendritically solidified sample showed that the highest Cr-rich area forms between the $\gamma / \gamma^{\prime}$ eutectic and interdendritic region, especially in the vicinity of the coarse $\gamma / \gamma^{\prime}$ eutectic (Figure 11(f)). Considering that the predominant phase comprising the $\gamma / \gamma^{\prime}$ eutectic is the $\gamma^{\prime}$ phase as shown in Figure 3(b) and the Cr concentration in the $\gamma^{\prime}$ phase is quite low, the fact that the solidification of the alloy CMSX-10 is completed with the formation of $\gamma / \gamma^{\prime}$ eutectic can not explain the Cr-rich area formed around the coarse $\gamma / \gamma^{\prime}$ eutectic. Therefore, it is suggested that there exists a final solidification reaction after the formation of $\gamma / \gamma^{\prime}$ eutectic in the alloy CMSX-10. This final solidification seems to be the formation of supersaturated $\gamma$ phase from the residual liquid after the $\gamma / \gamma^{\prime}$ eutectic reaction, because no other phases were found with the exception of thin $\gamma$ layer around the coarse $\gamma / \gamma^{\prime}$ eutectic, which was observed as a $\gamma^{\prime}$ precipitate free zone (PFZ) as shown in Figure 3(b).

The Cr-rich PFZ has been frequently observed near the $\gamma / \gamma^{\prime}$ eutectic in the as-cast microstructure of several Ni-base superalloys [32,33]. However, limited information is available in the literature about the detailed description of this phase. The formation of Cr-rich $\gamma$ layer appears to be strongly related to the

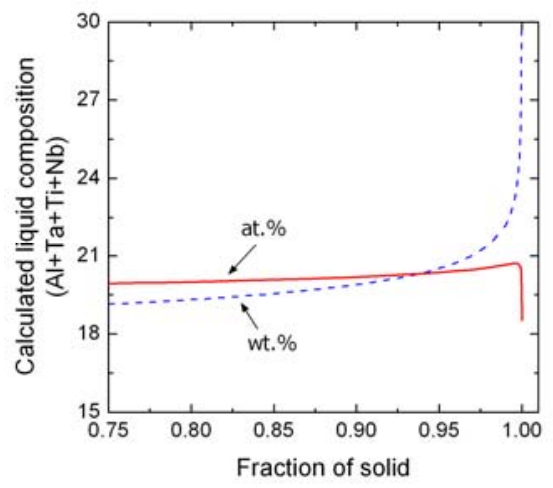

Figure 12. Calculated composition of the total $\gamma^{\prime}$ forming elements $(\mathrm{Al}+\mathrm{Ta}+\mathrm{Ti}+\mathrm{Nb})$ in the residual liquid using Scheil model with experimentally determined $k_{i}^{\gamma / \gamma^{\prime}}$ and $C_{e u}^{0}$ as input parameters. inverse segregation behavior of $\mathrm{Al}$ during the growth of $\gamma / \gamma^{\prime}$ eutectic. Among the $\gamma^{\prime}$ forming elements, only $\mathrm{Al}$ segregated to the growing $\gamma / \gamma^{\prime}$ eutectic, while the other $\gamma^{\prime}$ forming elements such as $\mathrm{Ta}, \mathrm{Ti}$, and $\mathrm{Nb}$ segregated to liquid during the solidification of $\gamma / \gamma^{\prime}$ eutectic (Figure 9 and Table III). Therefore, it is expected that the $\mathrm{Al}$ concentration would be continuously decreased, while the $(\mathrm{Ta}+\mathrm{Ti}+\mathrm{Nb})$ contents would be increased in the residual liquid as the $\gamma / \gamma^{\prime}$ eutectic solidification goes to the end. In addition, because the at. \% of $\mathrm{Al}$ is quite high among the $\gamma^{\prime}$ forming elements (Table III), the gradual decrease in $\mathrm{Al}$ concentration may eventually lead to the decrease in the total amount of $\gamma^{\prime}$ forming elements in the residual liquid below some critical limit that is necessary for the $\gamma / \gamma^{\prime}$ eutectic formation.

The decrease in the total amount of $\gamma^{\prime}$ forming elements during the solidification of $\gamma / \gamma^{\prime}$ eutectic could be predicted by Scheil model using Eq. (5). Figure 12 presents the calculated composition of the total $\gamma^{\prime}$ forming elements $(\mathrm{Al}+\mathrm{Ta}+\mathrm{Ti}+\mathrm{Nb})$ in the residual liquid predicted by Scheil model with experimentally determined $k_{i}^{\gamma / \gamma^{\prime}}$ and $C_{e u}^{0}$ as input parameters (Table III). It is clear from Figure 12 that the sum of $\gamma^{\prime}$ forming elements in wt. \% continuously increases. On the other hand, it was found that the composition in at. \% abruptly decreases near the end of solidification due to the strong decrease in $\mathrm{Al}$ concentration. For this reason, PFZ-like $\gamma$ layer shown in Figure 3(b) seems to be formed from the final residual liquid after the completion of $\gamma / \gamma^{\prime}$ eutectic reaction.

\section{CONCLUSIONS}

1. The measured solute compositions of planar solidified primary $\gamma$ in CMSX-10 alloy corresponded well to the calculated solute profiles predicted by Scheil model, i.e. the back-diffusion in solid was found to be small enough to neglect during the solidification with planar S/L interface.

2. In the dendritic solidification regimes ( $R \geq 5.0 \mu \mathrm{m} / \mathrm{s}$ ), the volume fraction of $\gamma / \gamma^{\prime}$ eutectic rapidly increased with increasing the solidification rate at lower rates of $R=5.0$ to 25 $\mu \mathrm{m} / \mathrm{s}$, while it showed a maximum plateau of about $25 \%$ irrespective of the solidification rate when the solidification rate is higher than $25 \mu \mathrm{m} / \mathrm{s}$. The maximum value of $25 \%$ agrees quite well with the $\left(1-f_{s}\right)$ in planar solidification condition, where $f_{s}$ corresponds to the fraction of solid that $\gamma / \gamma^{\prime}$ eutectic begins to form $\left(f_{s}=0.75\right)$. Considering the negligible backdiffusion occurring in planar solidification, the effect of backdiffusion on decreasing the severity of microsegregation in dendritic solidification was negligible when the solidification rate is higher than $25 \mu \mathrm{m} / \mathrm{s}$ (corresponding cooling rate, $G \cdot R=$ $20.7 \mathrm{~K} / \mathrm{min}$ ) in CMSX-10 alloy.

3. The partition coefficients during $\gamma / \gamma^{\prime}$ eutectic solidification of CMSX-10 were determined on the sample quenched during the planar solidification of $\gamma / \gamma^{\prime}$ eutectic. The elements Co, Cr, Mo, $\mathrm{Nb}, \mathrm{Re}, \mathrm{Ta}$, and $\mathrm{Ti}$ were found to be partitioned to liquid phase, while $\mathrm{Al}, \mathrm{W}$, and $\mathrm{Ni}$ partitioned to the growing $\gamma / \gamma^{\prime}$ eutectic. It is notable that $\mathrm{Cr}$, Mo, and $\mathrm{Nb}$ exhibited particularly strong segregation tendency during $\gamma / \gamma^{\prime}$ eutectic formation.

4. The compositional profiles of $\mathrm{Cr}$ in planar grown sample clearly revealed that $\mathrm{Cr}$-enriched area formed after the formation of $\gamma / \gamma^{\prime}$ eutectic. Based on the microstructural observation, low $\mathrm{Cr}$ solubility in $\gamma^{\prime}$ phase, and the results from EPMA analysis, it has been suggested that the final 
solidification of CMSX-10 alloy would be completed with the formation of supersaturated $\gamma$ layer.

\section{ACKNOWLEDGEMENTS}

This work was supported by National Research Laboratory Project of Korean Ministry of Science and Technology (MOST). One of the authors (SMSeo) is grateful to Japan Society for the Promotion of Science (JSPS) for the financial support through the Ronpaku fellowship.

\section{REFERENCES}

1. G.L. Erickson, "A New, Third-Generation, Single-Crystal, Casting Superalloy“, J. Metals., 47 (4) (1995), 36-39.

2. W.S. Walston et al., "Rene N6: Third Generation Single Crystal Superalloy”, Superalloys 1996, R.D. Kissinger et al., eds., TMS, Warrendale, PA, 1996, 27-34.

3. G.E. Fuchs, "Solution Heat Treatment Response of a Third Generation Single Crystal Ni-Base Superalloy", Mater. Sci. Eng. A, 300 (2001), 52-60.

4. M.S.A. Karunaratne et al., "Modelling of the Microsegregation in CMSX-4 Superalloy and Its Homogenisation during Heat Treatment”, Superalloys 2000, T.M. Pollock et al., eds., TMS, Warrendale, PA, 2000, 263-272.

5. T. Link et al., "Synchrotron Tomography of Porosity in SingleCrystal Nickel-Base Superalloys”, Mater. Sci. Eng. A, A425 (2006), 47-54.

6. T.M. Pollock and W.H. Murphy, "The Breakdown of SingleCrystal Solidification in High Refractory Nickel-Base Alloys", Metall. Mater. Trans. A, 27 (1996), 1081-1094.

7. R.A. Hobbs, S. Tin and C.M.F. Rae, "A Castability Model Based on Elemental Solid-Liquid Partitioning in Advanced Nickel-Base Single-Crystal Superalloys”, Metall. Mater. Trans. A, 36 (2005), 2761-2773.

8. Q. Feng et al., "Solidification of High-Refractory RutheniumContaining Superalloys”, Acta Mater., 51 (2003), 269-284

9. M.S.A. Karunaratne et al., "On the Microstructural Instability of an Experimental Nickel-Based Single-Crystal Superalloy", Metall. Mater. Trans. A, 32A (2001), 2409-2421.

10. R. Darolia et al., "Formation of Topologically Closed Packed Phases in Nickel Base Single Crystal Superalloys", Superalloys 1988, D.N. Duhl et al., eds., TMS, Warrendale, PA, 1988, 255264

11. M. Ganesan, D. Dye and P.D. Lee, “A Technique for Characterizing Microsegregation in Multicomponent Alloys and Its Application to Single-Crystal Superalloy Castings", Metall. Mater. Trans. A, 36 (2005), 2191-2204.

12. M.N. Gungor, "A Statistically Significant Experimental Technique for Investigating Microsegregation in Cast Alloys”, Metall. Mater. Trans. A, 20A (1989), 2529-2533.

13. R.A. Hobbs et al., "Solidification Characteristics of Advanced Nickel-Base Single Crystal Superalloys”, Superalloys 2004, K.A. Green et al., eds., TMS, Warrendale, PA, 2004, 819-825.

14. A. Thirumalai, A. Akhtar, and R.C. Reed, "Extent of Back Diffusion during Solidification of Experimental Nickel Based Single Crystal Superalloy”, Mater. Sci. Tech., 22 (2006), 1-13.

15. J. Lacaze, P. Benigni, and A. Howe, "Some Issues Concerning Experiments and Models for Alloy Microsegregation”, Adv. Eng. Mater., 5 (2003), 37-46.

16. P.K. Sung and D.R. Poirier, "Liquid-Solid Partition Ratios in Nickel-Base Alloys”, Metall. Mater. Trans., 30A (1999), 21732181.
17. S.N. Tewari et al., "Solutal Partition Coefficients in NickelBased Superalloy PWA-1480”, Mater. Sci. Eng., A141 (1991), 97-102.

18. V.A. Wills and D.G. McCartney, "A Comparative Study of Solidification Features in Nickel-Base Superalloys: Microstructural Evolution and Microsegregation”, Mater. Sci. Eng. A, A145 (1991), 223-232.

19. S.M. Seo et al., "Eta Phase and Boride Formation in Directionally Solidified Ni-Base Superalloy IN792+Hf”, Metall. Mater. Trans. A, 38A (2007), 883-893.

20. Y. Zhu et al., "A New Way To Improve The Superalloys", Superalloys 1992, S.D. Antolovich et al., eds., TMS, Warrendale, PA, 1992, 145-154.

21. R. Trivedi et al., "Directional Solidification Microstructures in Diffusive and Convective Regimes”, J. Cryst. Growth, 222 (2001), 365-379.

22. W. Kurz and D.J. Fisher, Fundamentals of Solidification (Trans Tech Publ. Ltd., Switzerland, 4th Ed., 1998), 117.

23. R.M. Kearsey et al., "Compositional Design Consideration for Microsegregation in Single Crystal Superalloy Systems", Intermetallics, 12 (2004), 903-910.

24. Y. Zhu et al., "Superalloys with Low Segregation", Superalloys 1988, D.N. Duhl et al., eds., TMS, Warrendale, PA, 1988, 703-712.

25. E. Scheil, Z. Metallkd., "Bemerkungen zur Schichtkristallbildung“, 34 (1942), 70-75.

26. H.D. Brody and M.C. Flemings, "Solute Redistribution in Dendritic Solidification”, TMS-AIME, 236 (1966), 615-624.

27. N. El-Bagoury et al., "Influence of Rhenium and Cooling Rate on the Solidification of Ni Base Superalloys, Inconel 718", Mater. Trans. JIM, 46 (2005), 909-915.

28. D.M. Stefanescu, Science and Engineering of Casting Solidification (Kluwer Academic/Plenum Publishers, NY, 2002), 42.

29. C. Walter et al., "Simulation of the Solidification of CMSX-4", Mat. Sci. Eng., A397 (2005), 385-390.

30. N. Warnken et al., "Investigation of Eutectic Island Formation in SX Superalloys“, Mater. Sci. Eng., A413-414 (2005), 267271.

31. N. D’Souza and H.B. Dong, "Solidification Path in ThirdGeneration Ni-Based Superalloys, with an Emphasis on Last Stage Solidification”, Scr. Mater., 56 (2007), 41-44.

32. B.G. Choi et al., "Eta Phase Formation during Thermal Exposure and Its Effect on Mechanical Properties in NickelBase Superalloy GTD 111”, Superalloys 2004, K.A. Green et al., eds., TMS, Warrendale, PA, 2004, 163-171.

33. W.R. Sun et al., "Relationship between Eta Phase Formation and Solidification Rate in Directionally Solidified IN792+Hf Alloy”, Mater. Sci. Tech., 15 (1999), 1221-1224. 